\title{
THE USE OF 3D SCANNING METHODS TO EVALUATE THE HYBRID LAYER USED IN FORGING TOOLS IN ORDER TO IMPROVE THEIR DURABILITY
}

\begin{abstract}
This study is focused on tools used in the industrial process of hot forging of a front wheel forging (gear wheel) manufactured for the automotive industry. Five different variants were applied for the tools: 3 die inserts were coated with three different hybrid layers (PN + PVD type), i.e. AlCrTiN, AlCrTiSiN and CrN, one insert was only nitrided, and one was pad welded, to improve tool durability. The tool wear was analysed and represented by the material degradation on the working surface, based on the 3D scanning and the material growth of the periodically collected forgings. Additionally, the scanned tools were divided into two areas, in which it was found, based on the analysis, that various degradation mechanisms are predominant. Microstructural tests and hardness measurements of the analyzed tools were also performed. Based on the results, it was found that, in the central part of the die insert, thermo-mechanical fatigue, abrasive wear and plastic deformation occurred, while in the area of the bridge insert, only abrasive wear could be observed. For these areas, the loss of material was determined separately. It was established that the use of the $\mathrm{GN}+\mathrm{CrN}$ and $\mathrm{GN}+\mathrm{AlCrTiN}$ hybrid layers on forging tools improves their durability, while the best results in the central area were observed on the tool with the $\mathrm{GN}+\mathrm{CrN}$ layer, which is the most resistant to thermo-mechanical fatigue. In the second analyzed area, good wear resistance occurred on $\mathrm{GN}+\mathrm{CrN}, \mathrm{GN}+\mathrm{AlCrTiN}$ and pad welded inserts, for which, together with the increase of the forging number, a proportional, slight growth of the loss of material occurred.
\end{abstract}

Keywords: Forging process, Destructive phenomena, Durability of tools, Scanning, Hybrid layers

\section{Introduction}

Forging tools used in hot forging processes work under very hard, if not extreme, conditions: periodically, the mechanical loads reach even up to $1000 \mathrm{MPa}$ and the thermal conditions - from $60^{\circ} \mathrm{C}$ to $800^{\circ} \mathrm{C}$ at the surface [1]. That is why they are exposed to the operation of many destructive factors, which cause their wear. The areas especially exposed are the working surface and the surface layer of the tool, and so, most of the mentioned destructive mechanisms refer to these tool areas [2]. The most commonly occurring (also the been tested) destructive mechanisms are: plastic deformation and abrasive wear in warm forging [3] and hot forging processes [4], thermal fatigue cracking [5-7] and thermo-mechanical fatigue [8]. Among them, the most extensively studied one is the mechanism of wear is abrasive wear, which prevails also in the process for cold forging $[9,10]$. For example, a comprehensive analysis of the major destructive mechanisms of tools in the forging process of car steering was presented in work [11]. In order to avoid those phenomena, various methods are used, which usually consist in producing or applying appropriate protective layers, the task of which is the protection from one or more destructive mechanisms $[2,12]$.
At present, the most commonly used, and one of the cheapest, methods of improving forging tool durability is nitriding. Despite the fact that this method is well-known and well-mastered, it does not always provide a clear effect of durability improvement. That is why other methods are being searched for to improve tool durability in forging processes, which are more effective, yet more expensive as well $[12,13]$. The most recent methods include undoubtedly hybrid technologies, consisting in the use of two or more surface engineering techniques. There are experiments on composition of tool material connected with cryogenic treatment [14], combination of different types of heat treatment [15], several attempts in the application of the hard PVD coating directly on a metal [16] and many other described in book [17]. Hybrid techniques can combine e.g. thermo-mechanical treatment methods and one of the PVD techniques. This technology makes it possible to provide the surface with the appropriate performance properties and to create a barrier which will effectively limit the influence of the destructive factors [18]. This subject was also tested by authors in previous works [19], where they have found the advantage of using hybrid layers. Hybrid layers were successfully applied in bulk metal forming [20], diecasting [21] and hot forging [22]. Another technology which can significantly improve forging tool durability is pad welding [26].

\footnotetext{
* WROCLAW UNIVERSITY OF SCIENCE AND TECHNOLOGY, DEPARTMENT OF METAL FORMING AND METROLOGY, 5-7 ŁUKASIEWICZA STR, 50-371 WROCŁAW, POLAND

** INSTITUTE FOR SUSTAINABLE TECHNOLOGIES - NATIONAL RESEARCH INSTITUTE, 6/10 PUŁASKIEGO STR., 26-600 RADOM, POLAND

* Corresponding author: marek.hawryluk@pwr.edu.pl
} 
The latter consists in coating the forging tools with a metal layer by means of the welding technique with a simultaneous melting of the substrate. The basic task of the pad welding technology is ensuring the possibly best performance properties of the coating, with the possibly lowest costs, that is, prolonging the total operation time by way of prevention (enrichment) or repair (regeneration of the used components). In the literature, durability, from the production point of view, is usually meant as the number of forgings which fulfill the quality requirements, produced with the use of the given tool. From the scientific point of view, in turn, the durability of the tool is connected with its resistance to destructive factors occurring during its performance. In this case, it is very important to perform an objective evaluation and analysis of the destructive mechanisms which cause tool wear or destruction, instead of a subjective evaluation of the operator, as is the case of the definition used for the production. Tool durability is a complex issue, and tool wear significantly lowers the quality of the produced forgings. This subjects were widely described by authors in following works [23-25]. In the work [24], the author concentrates on selected methods, which provide the highest effectiveness in the improvement of the forging tool life, used in the industrial processes of die forging, based on own research and experiments realized in cooperation with the forging industry. The most frequent forging defects caused by wear are errors in the filling of the die impression, that is: incomplete forging, laps, burrs, bends, scratches, delaminations, micro- and macro-cracks, etc. This, in turn, affects the functionality of the final product created from the forging [25].

The study compares and analyzes the effect of the use of selected hybrid coatings (gas nitrided layer + PVD coating type), a nitrided layer and a pad welded die insert on the durability of a forging tool (especially for two main selected areas) used in the process of hot die forging of a wheel.

In order to determine the degree of wear (loss of material) of the analyzed tools, during the performance tests, the newlyelaborated reverse 3D scanning method was applied, consisting in a measurement of the progressing wear of the selected forging tool (its loss of material), by means of a scanner, based on the changes in the shape of the forgings periodically collected from the process (forging material growth). During the short technological breaks, the performed measurements of the forging shape changes are verified by means of a direct measurement of the tool wear, with the use of a measuring arm with an integrated laser scanner. A detailed analysis of the mechanisms was performed on the basis of the structural tests.

The applied methods of analysis presented above enable an objective evaluation of the effectiveness of hybrid layers in the improvement of the durability of tools used in industrial forging processes.

\section{Research material}

For the investigations, the process of hot forging of a front wheel forging was selected (Fig. 1c). The wheel, after toothing, is used in the gear box as the front wheel of the reverse gear in motorcars.

The analyzed process is realized on a crank press of the nominal force of $25 \mathrm{MN}$, in three forging operations (Fig. 1a): operation I - upsetting, operation II - roughing and operation III - finishing forging. The forged material is C45 steel, in the shape of a cylinder. The initial temperature of the charge material equals $1150^{\circ} \mathrm{C}$. In the analyzed process, the tools are made of WCL steel. After the thermal treatment, the tools for the second and third operation undergo standard gas nitriding. Before the process, they are preliminarily heated by a scrap material to the temperature of $250^{\circ} \mathrm{C}$. A detailed analysis was performed on the lower die insert used in the second forging operation, the durability of which is the lowest in the analyzed process, that is 7000 forgings (Fig. 1b).

\section{Test methodology}

In order to improve tool durability, coating with a hybrid layer of the nitrided layer/PVD coating type was applied. Three variants of the coating were selected, i.e. AlCrTiN, AlCrTiSiN and $\mathrm{CrN}$. Additionally, with the purpose to compare the selected hybrid layers with the other tools, two extra inserts were tested. On one of them, a thermo-chemical treatment was applied, consisting in the traditional gas nitriding, whereas the other one underwent regenerative pad welding with the powder wire Welding Alloys Hardface DCO ø1,2 mm. The tools prepared in this way underwent performance tests under the industrial conditions of Kuźnia Jawor S.A. (Jawor Forge). Table 1 presents the properties of the obtained nitrided layer being part of the hybrid
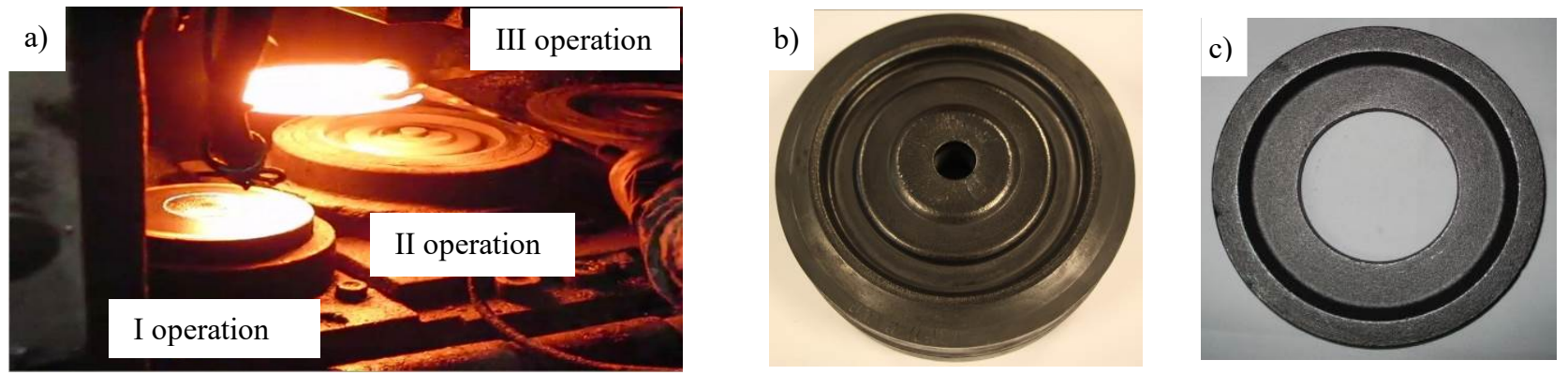

Fig. 1. View of the forging process: a) tools used in the front wheel forging installed on a press, b) lower die insert for operation II c) a ready front wheel forging (after punching and trimming, before toothing) 
Properties of the surface layer of the examined die inserts

\begin{tabular}{|c|c|c|c|c|c|c|}
\hline & & GN+AlCrTiN & GN+AlCrTiSiN & GN+CrN & GN layer & Pad welded layer \\
\hline \multirow{3}{*}{ Coating } & Thickness $[\mu \mathrm{m}]$ & $\approx 6,5$ & $\approx 3,0$ & $\approx 8,0$ & \multirow{3}{*}{ - } & \multirow{4}{*}{$\begin{array}{l}\approx 5 \mathrm{~mm} \\
600 \mathrm{HV}\end{array}$} \\
\hline & Hardness & $3250 \pm 315$ & $3240 \pm 430$ & $2100 \pm 140$ & & \\
\hline & Young modulus [GPa] & $360 \pm 25$ & $380 \pm 60$ & $215 \pm 25$ & & \\
\hline GN layer & Thickness & \multicolumn{4}{|c|}{$\mathrm{g}_{800} \approx 70 \mu \mathrm{m}$} & \\
\hline
\end{tabular}

layer, as well as the properties of the applied PVD coatings and the pad welded layer.

Next, after the operation, the tools were cleaned and tested by way of: a macroscopic analysis combined with scanning, a microstructure analysis and microhardness tests.

\section{Macroscopic analysis combined with scanning}

For the analysis, inserts which had produced similar numbers of forgings were selected, except for the nitrided insert, which was at an earlier stage of the operation process. During the inserts' performance, their wear was observed, and, in particular, the state of their surface was recorded based on the surface state of the periodically collected forgings. The performed macroscopic analysis of the die inserts after their operation showed that, in different areas of the particular die inserts (Fig. 2), changes on the surface occured. On all the inserts, in the front area, cracks were observed, caused by thermal and thermo-mechanical fatigue, and also, for some inserts after a larger number of forgings (the pad welded insert, inserts with the AlCrTiSiN, and AlCrTiSiN layers), clear traces of abrasive wear were recorded, the wear having been intensified by fatigue. On the bridge, in turn, for each insert, a strong abrasion of the radius on the whole perimeter could be observed, which was particular on insert with $\mathrm{GN}+\mathrm{CrN}$ layer (Fig. 2d).

What is more, depending on the type of the applied protective layer, in the front part, different intensities of the destructive mechanisms were observed. The die insert after pad welding exhibits a very good resistance to deep cracking and plastic deformation, and its wear proceeds gradually, without strong spalling of the surface layer. The tools with the PVD coatings wear in two stages: formation of a crack network with the simultaneous withholding of the abrasive wear, and spalling of deep cracks and accelerated abrasive wear on the whole front surface, leading to a complete elimination of the surface layer. The AlCrTiN and AlCrTiSiN coatings (Fig. 2b,c) exhibit the tendency for deep radiating cracks, as well as accelerated spalling and abrasion of the front surface. In the case of the insert with the AlCrTiN coating (Fig. 2c), the crack network is finer, and the surface layer remains on the tool for a longer time.

The CrN coating seems to be the most resistant to fatigue failures in the analyzed area, because the crack network is dense, yet not so deep (Fig. 2d) and the surface layer remains on the tool till the end. For the die insert with the nitrided layer, a network of fine cracks was also observed, but the abrasive wear occurred the soonest as local wear, which gradually covers the examinated area. What is more, deep local spalling propagating
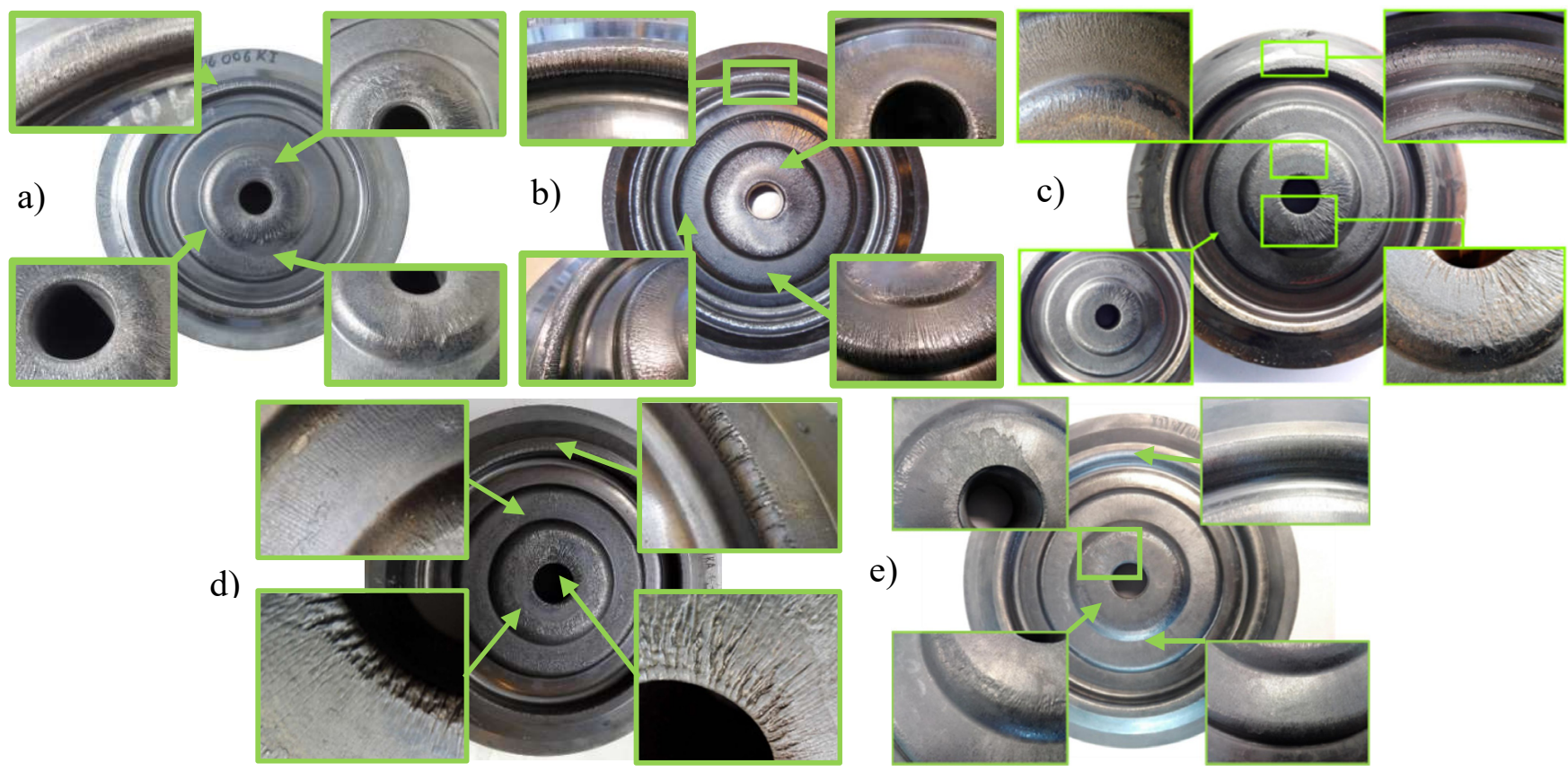

Fig. 2. View of the macro-analyzed insert dies: a) pad welded, b) with the GN $+\mathrm{AlCrTiN}$ layer, c) with the GN $+\mathrm{AlCrTiSiN}$ layer, d) with GN+CrN layer, e) with the nitrided layer 
from the inside is the most undesirable type of wear, due to its unpredictability and size.

Another investigated location is the area around the die bridge on the radius, near the gap through which the flash is filtered. In this area, as a result of the intensive flow of the forging material into the groove on the flash, a total abrasion occurs on the whole perimeter of the die. The wear is so deep that, for all the inserts, i.e. the ones both with the coatings and the nitrided layer, the protection layers have been probably completely eliminated, except for the die insert with the CrN coating. After the loss of the nitrided layer, the material is eliminated much faster and deep grooves are also formed. Only the pad welded layer, applied at the depth of about $5 \mathrm{~mm}$, despite a significant loss of material, remains till the end of operation time, limiting the abrasive wear to the minimum. The best results are obtained for the die insert with the $\mathrm{GN}+\mathrm{CrN}$ layer and for the pad welded insert.

In order to perform a quantitative evaluation of the state of the surface, the impressions of the analyzed die inserts underwent scanning.

For the measurements of the geometrical changes of the forgings, the measuring arm ROMER Absolute ARM 7520si was used (Fig. 3), together with the Polyworks software and the Real Time Quality Meshing technology. The arm makes it possible to perform classic measurements with the use of a measuring probe as well as non-contact measurements with the use of a linear laser scanner RS3, integrated with the arm, with the declared accuracy at the level of 2 sigma $30 \mu \mathrm{m}$.

For the determination of the wear degree (loss of material) of the analyzed tools, during the performance tests, the reverse 3D scanning method was applied, consisting in performing a measurement, with the use of a scanner, of the proceeding wear, that is the loss of material of the selected forging tool, based on the forging shape changes of the samples on which the material grew, periodically collected from the process.

This method was discussed in detail in the study [23], in which the authors analysed and validated it based on the hot forging process of a lid forging.

According to this method, the authors conducted research of the die insert wear using the reverse 3D scanning method. Fig. 4 presents scans with the analysed worn die inserts.

The authors observed that the lowest total wear, both on the bridge and the front surface, was in the case of the insert with the $\mathrm{GN}+\mathrm{CrN}$ layer. Based on the scan images (Fig. 4), we can also compare the loss of material with the CAD model, in the case when it is impossible to scan a new tool before forging.
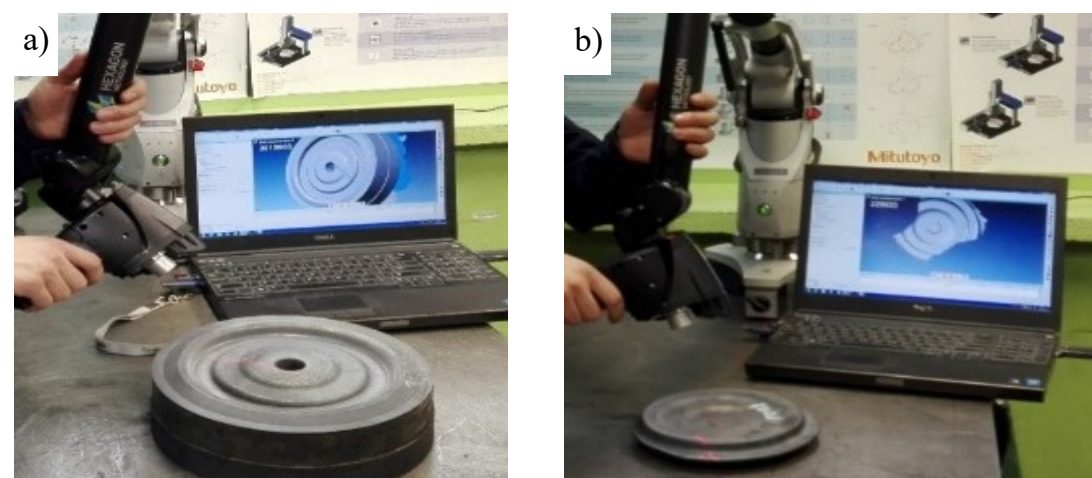

Fig. 3. The pictures: a) scanning of the selected die insert with the ROMER Absolute ARM 7520si measuring arm, equipped with an integrated laser scanner $b$ ) a forging selected for the scanning analysis
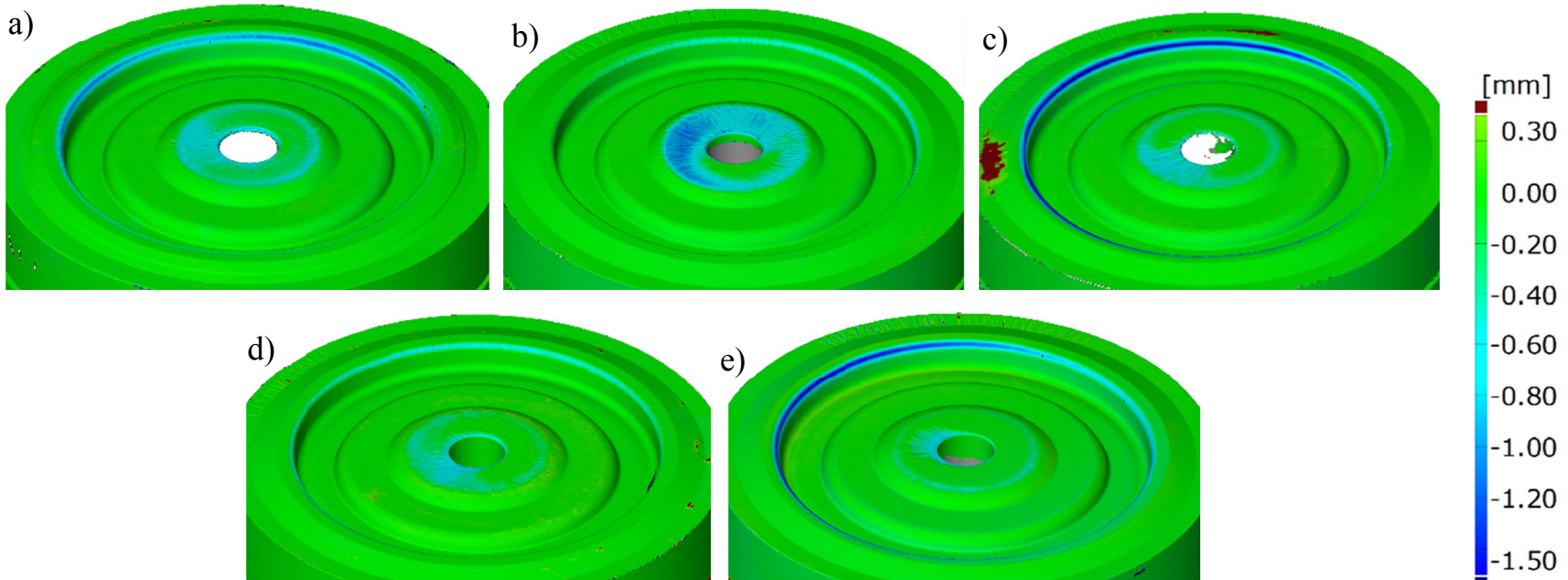

Fig. 4. Scan images of worn die inserts: a) pad welded after 6900 forgings, b) with GN+ALCrTiN layers after 8000 forgings, c) with GN+ALCrTiSiN layers after 6500 forgings, d) with GN+CrN layer after 7000 forgings, e) only gas nitrided (GN) after forging 4000 itmes 
The compilation of the results presented in Fig. 5 confirms the diverse wear mechanisms in the analyzed areas, caused by the differences in the properties of the material used for the forging dies. We can see that the $\mathrm{GN}+\mathrm{CrN}$ layer inserts make is possible to obtain the minimal loss value, i.e. $1498\left[\mathrm{~mm}^{3}\right]$ in the case of producing 7000 forgings. Small values of the loss of material, yet two times higher, can be observed for the pad welded dies, which equal about $3120\left[\mathrm{~mm}^{3}\right]$ in the case of producing 6900 forgings. The dies coated with GN+ALCrTiSiN obtained the highest values of the sum of the material loss, i.e. $6145\left[\mathrm{~mm}^{3}\right]$, yet, they made it possible to obtain 6500 forgings.

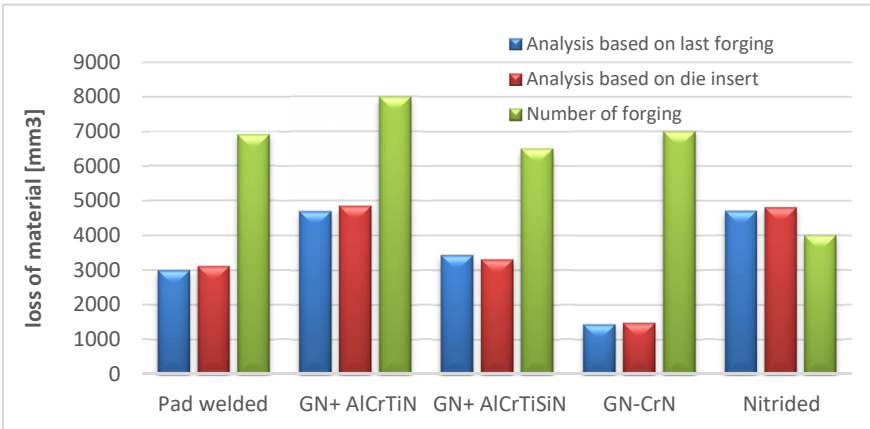

Fig. 5. Compilation of the total material losses considered separately for the last forging and the worn die inserts together with the number of forgings

In the current work, the authors expanded the reverse 3D scanning method used so far. For the analyzed tool, two main areas were selected, for which, based on the preliminary analysis, it was found that different destructive mechanisms were predominant. The preliminary analysis, confirmed by other tests, showed that, in a complex analysis, the whole loss of material of the tool, based on the periodically collected samples, does not increase together with the increase of their number. A thorough analysis of the scanning results showed that, as the selected tool is used in the second operation (roughing), sometimes, the forging may not be fully shaped and, during the scanning process, a loss of material is observed instead of its growth. This, however, does not mean that the tool is defected, but it can point to a defect (incomplete filling) of the forging. This made the authors resolve to determine the loss of material separately for the selected areas. Fig. 6 presents a diagram of the proposed method. As reference surfaces for the die insert and the forging during scanning, the surfaces which had not worn during the forging process were adopted.

It should be emphasized that the scanning results obtained on the basis of the periodically collected forgings, for the last sample, were verified based on the actual loss of material on the worn out insert.

Fig. 8 shows the loss of material, based on the scanning results (forging) from the front of the analyzed die inserts - area A, whereas Fig. 9 - from the bridge -area B.

In the analysis of the volumetric wear calculated based on the forgings in the analyzed area A of the die insert front, we can

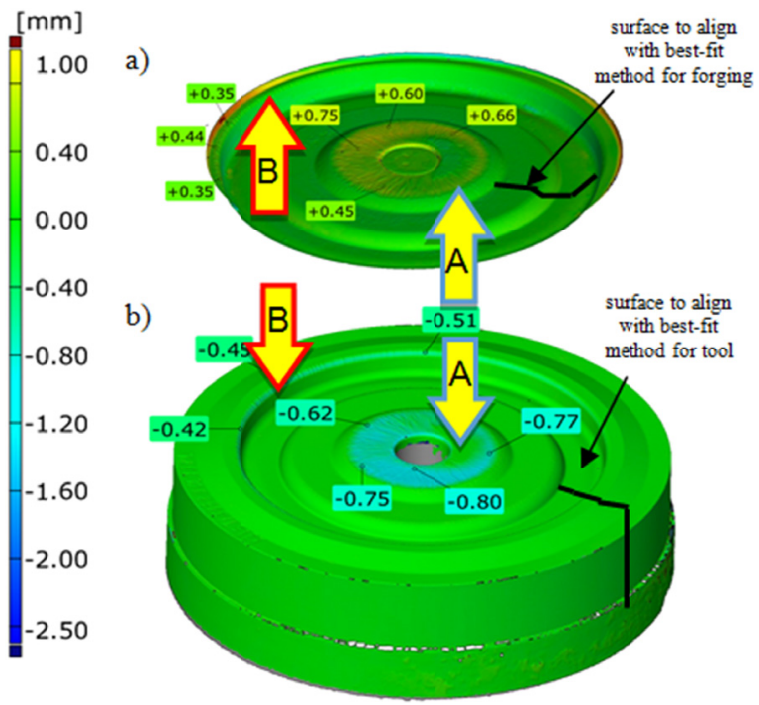

Fig. 6. Diagram of the proposed 3D scanning method. Division into the selected areas A (front) and B (bridge) marked in the comparison of the scan image of a) the GN+AlCrTiN die, b) the last forging produced on this die, with the 100th one

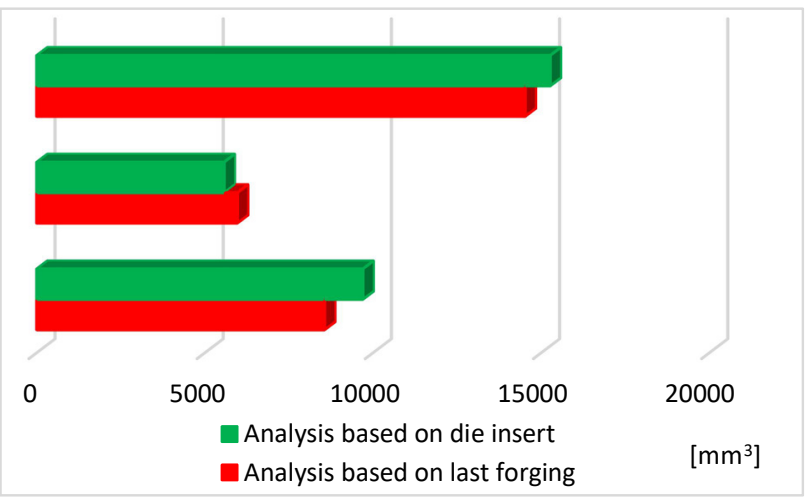

Fig. 7. Compilation of the results of the volume loss/ growth for the die and the last forging, with a division into the analyzed areas, for the die insert with the GN+AlCrTiN layer

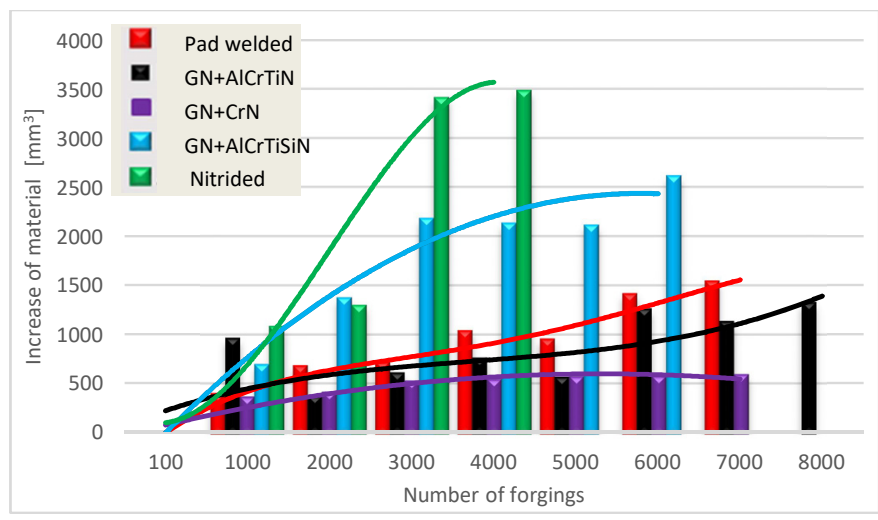

Fig. 8. Compilation of the results of the volumetric wear calculated based on the forgings in the analyzed area A of the insert front

see that the $\mathrm{GN}+\mathrm{CrN}$ layer exhibits the lowest wear, equaling $890\left[\mathrm{~mm}^{3}\right]$ in the tool working range of up to 7000 forgings. Bigger, but still satisfying values are obtained by the pad welded and GN+AlCrTiN dies, which, additionally, made it possible to 


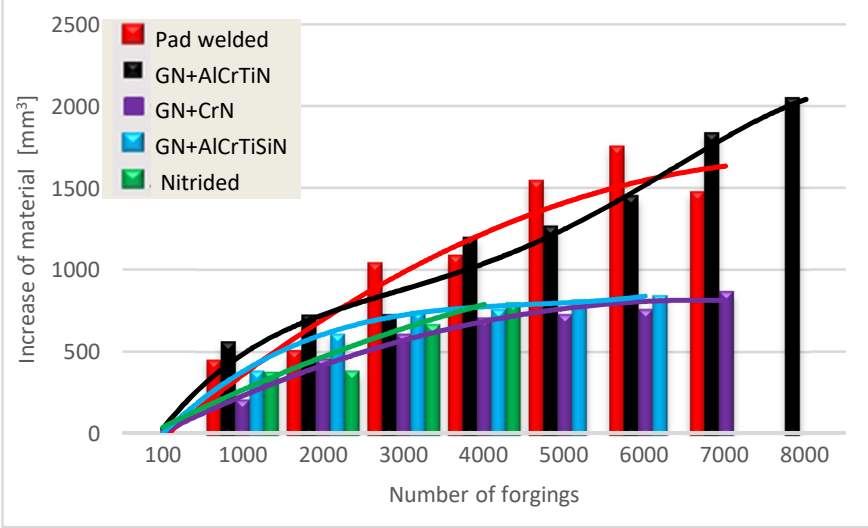

Fig. 9. Compilation of the results of the volumetric wear calculated based on the forgings in the analyzed area $\mathrm{B}$ on the die bridge

obtain a higher number of forgings, i.e. $6900 / 8000$ items, with similar values of volumetric wear $1500\left[\mathrm{~mm}^{3}\right]$. In the case of the diagrams for the dies with the applied coatings, we can notice similar values of wear in the die working range of up to 4000 forgings and a significant prolongation of durability in the case of the tool with the GN+AlCrTiN and GN+CrN coatings, which made is possible to produce $7000-8000$ forgings fulfilling the quality requirements of the process.

In the analysis of the diagram of volumetric wear calculated based on the forgings in the analyzed area B of the die bridge, for insert dies, we can notice that, this time, the GN+AlCrTiN and pad welded dies exhibit a higher wear, equalling $1600\left[\mathrm{~mm}^{3}\right]$ in the die working range of up to 7000 forgings, and the other dies, with the GN+CrN and GN+AlCrTiSiN hybrid layers, make it possible to obtain a lower loss of material at the maximal level of $600\left[\mathrm{~mm}^{3}\right]$, at the same time, producing about 7000 forgings. In the analysis of the process of wear of the dies with the coatings, we can notice very similar characteristics and possibilities of improving die durability to even 8000 items for the $\mathrm{GN}+\mathrm{AlCrTiN}$ coating, simultaneously, with steady wear, making it possible to obtain forgings with the acceptable geometry.

On the basis of the macroscopic analysis, we can establish that, in the central part of the die insert (area A), thermo-mechanical fatigue and abrasive wear occurred. In the area of the bridge (area B), in turn, only abrasive wear was observed. This was also confirmed by the microstructural tests and the hardness measurements performed at the further stage of the research.

\section{Microscopic analysis}

With the purpose to perform a microstructural analysis, for each analyzed die insert, a representative sample was cut out lengthwise (from the axis to the tool perimeter), on which the characteristic areas (control points) were marked for detailed tests (Fig. 10).

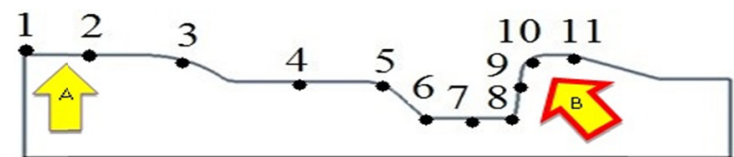

Fig. 10. Diagram of the representative sample with the marked control points

Figures 11-14 show the images taken by means of a metallographic microscope in points no. 2 and 3, as well as 9 and 10, for each die insert.

The images were taken with an optical microscope, at the magnification of $500 \times$. On the front surface (Figs. 11,12), abrasion of the surface layer occurred. In the pad welded insert (a), partial wear of the pad welded layer was observed, as well as plastic deformation on the surface, which can be observed on the deformed cracks. The dies with the hybrid layers partially protected the nitrided layer, which, however, exhibited a tendency
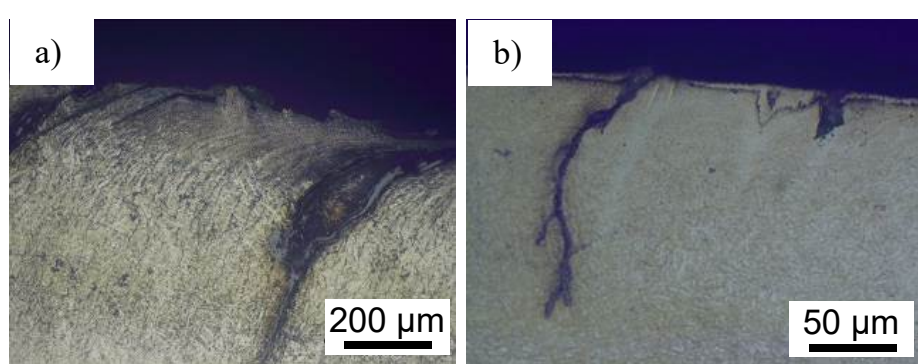

c)

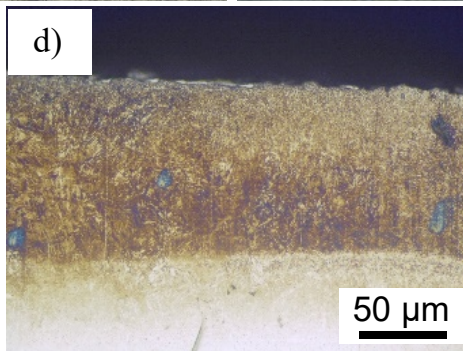

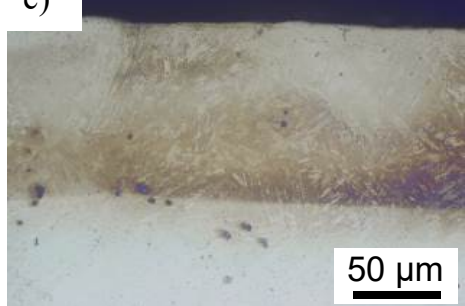

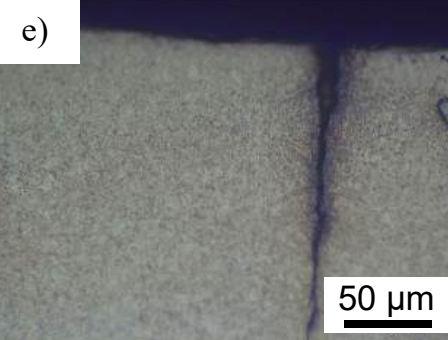

Fig. 11. Microstructures of the die in point no. 2: a) pad welded, b) with the GN+AlCrTiN layer c) with the GN+AlCrTiSiN layer, d) with GN+CrN layer, e) nitride 

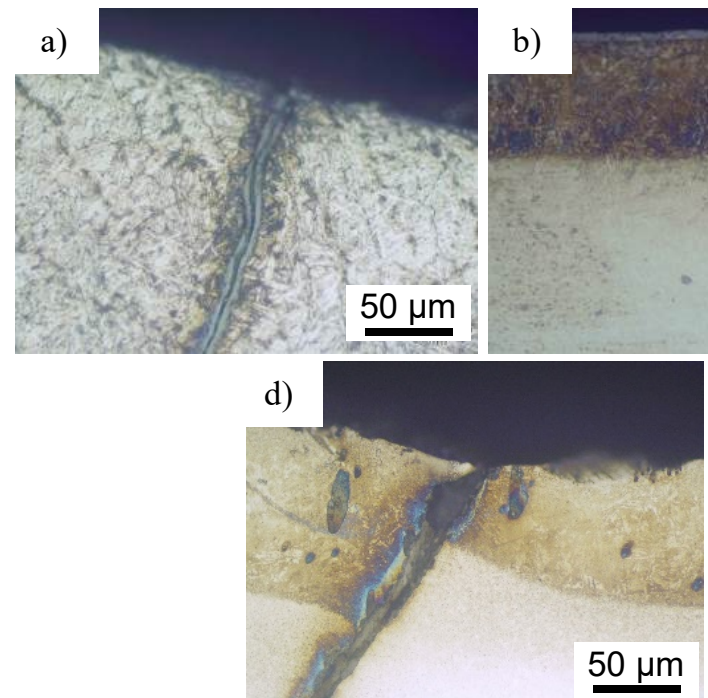

b)

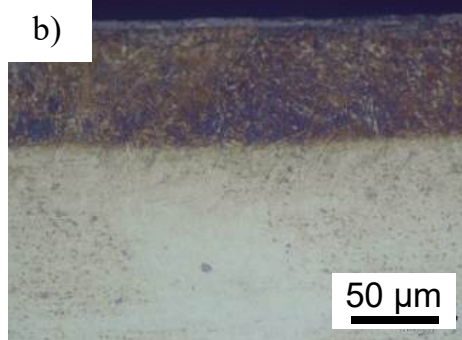

e)

Fig. 12. Microstructures of the die in point no. 3: a) pad welded, b) with the GN+AlCrTiN layer c) with the GN+AlCrTiSiN layer, d) with $\mathrm{GN}+\mathrm{CrN}$ layer, e) nitride

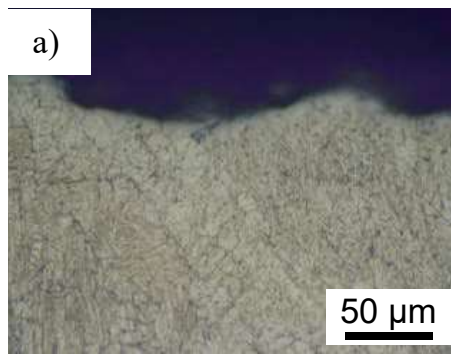

d)

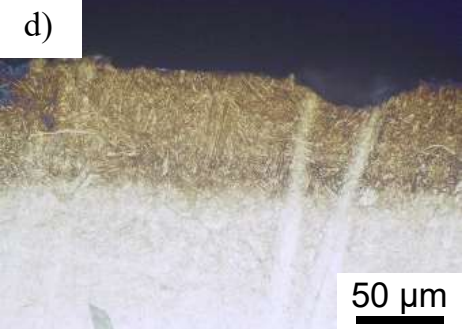

c)

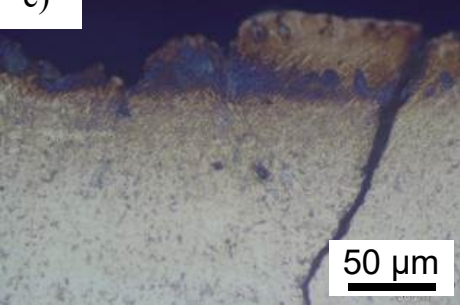

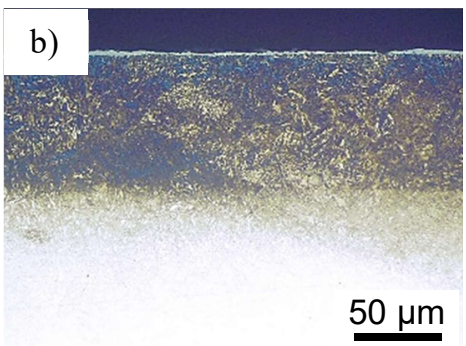

c)

e)

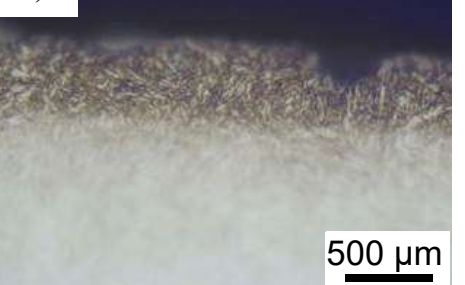

Fig. 13. Microstructures of the die in point no. 9: a) pad welded, b) with the GN+AlCrTiN layer c) with the GN+AlCrTiSiN layer, d) with $\mathrm{GN}+\mathrm{CrN}$ layer, e) nitride

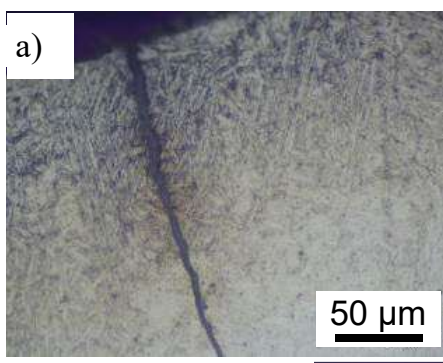

d)

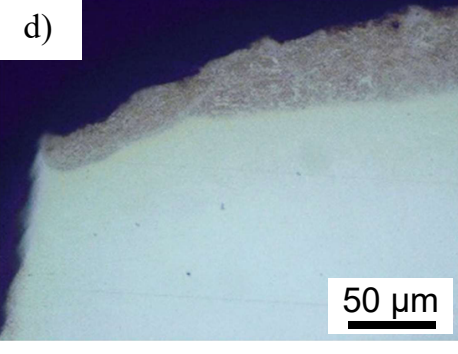

b)
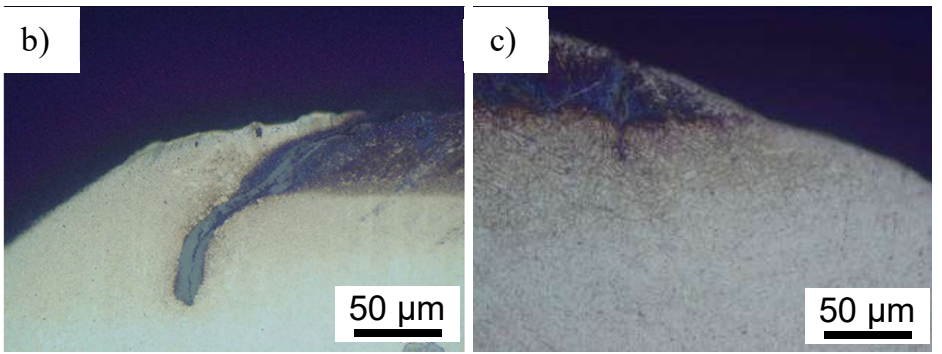

e)

Fig. 14. Microstructures of the die in point no. 10: a) pad welded, b) with the GN+AlCrTiN layer c) with the GN+AlCrTiSiN layer, d) with $\mathrm{GN}+\mathrm{CrN}$ layer, e) nitrided 
for spalling in the crack area. The best effect of protection was observed for the $\mathrm{GN}+\mathrm{CrN}$ layer and partially for the $\mathrm{GN}+\mathrm{AlCrTiN}$ layer. The die which was traditionally nitrided exhibited a faster and more facilitated wear caused by the destructive factors. In the vicinity of point no. 10, one can see a complete abrasion of the nitrided layer, whereas the pad welded layer was preserved. We can also see deep cracks on the radius of the die. At the same time, of all the applied coatings (Fig. 14a-c), the layer with the $\mathrm{GN}+\mathrm{AlCrTiN}$ coating exhibits a higher abrasive wear resistance, crack resistance and resistance to spalling. The lower durability of the die with the GN+AlCrTiSiN layer can be caused by the highest hardness of its PVD coating and its less thickness, and so it can be more susceptible to cracking and spalling.

\section{SEM analysis}

A detailed analysis of the changes in the surface layer of the analyzed tools was performed with the use of the scanning microscope TESCAN VEGA 3. This study presents exemplary results of the analysis of the areas marked in Fig. 10, which included the front surface (point no. 2 and 3), as well as the vicinity of the die bridge (points no. 9 and 10). In the first area (Fig. 15), differences in the wear character of the particular dies were observed. In each die, the presence of a thermo-mechanical crack network was found, which, after the tempering of the surface layer, underwent plastic deformation. In the pad welded die, the abrasive wear proceeded steadily and it was minor in comparison with the other dies. In the nitrided layer, the wear was the highest and it included, beside abrasion, also some significant plastic abrasions.

The dies with the AlCrTiN and AlCrTiSiN coatings only partially maintained their hybrid layer, while, usually, after 3-4 thousand forgings were produced, spalling as well as a loss of whole fragments of the layer were observed. Only one insert, the one covered with the $\mathrm{CrN}$ layer, maintained nearly all the hybrid layer till the end and did not undergo abrasion in this area, while only cracks were observed on its surface (Fig. 15d). In the vicinity of the bridge (Fig. 16), the wear mechanism is similar; however, differences in the degree of wear are visible. In the pad welded die, the loss of material was clearly the lowest, as the layer with an elevated hardness was present to the depth of $5 \mathrm{~mm}$ and it limited the friction throughout the whole operation period. On the surface, one can see deep smoothed grooves, caused by abrasive wear. The dies with the coatings were covered with cracks on the whole perimeter, and next, they lost the whole surface layer and their further wear proceeded very fast, similarly to the nitrided die. However, there are visible differences between the wear mechanisms of each protective layer.
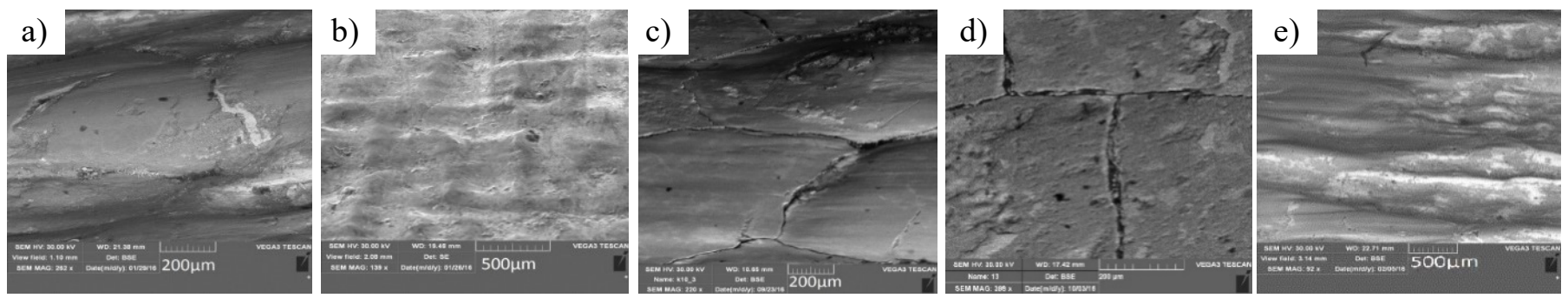

Fig. 15. SEM of the die front surface: a) pad welded, b) with the GN+AlCrTiN layer c) with the GN + AlCrTiSiN layer, d) with GN+CrN layer, e) nitride
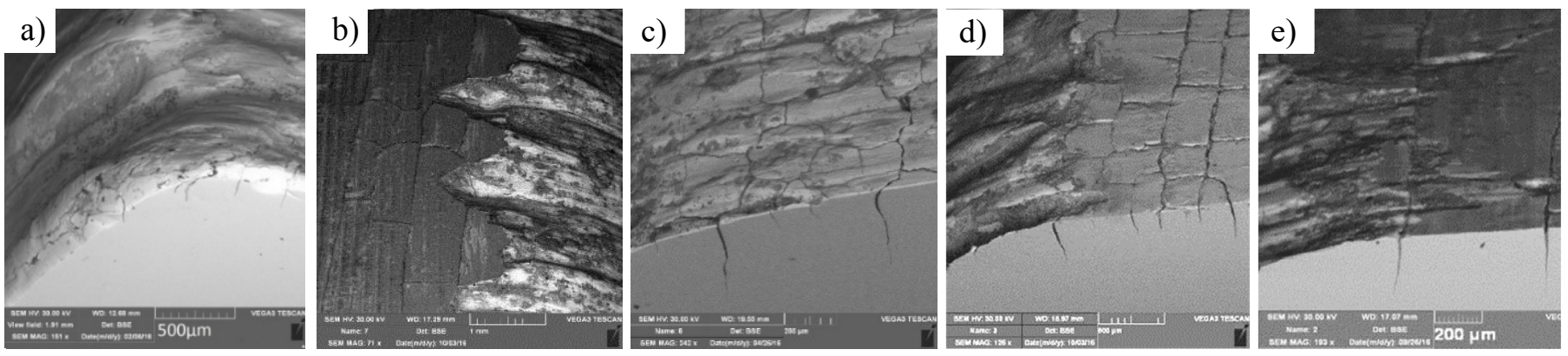

Fig. 16. SEM on the die bridge a) pad welded, b) with the GN+AlCrTiN layer c) with the GN+AlCrTiSiN layer, d) with GN $+\mathrm{CrN}$ layer, e) nitride

\section{Microhardness measurements}

The microhardness measurements by means of the Vickers method were performed in the direction from the working surface on the section of $1,5 \mathrm{~mm}$ towards the inside of the tool, with the load of $100 \mathrm{~g}$. The test was conducted in 4 selected points, marked in Fig. 10 as no. 2 and 3 (front surface), as well as 9 and 10 (vicinity of the die bridge). Figures $17-18$ show the measurement result for the analyzed dies.

On the basis of the microhardness results, we can see that, for all the inserts in area A, especially in point no. 2 (Fig. 17a), a clear drop of hardness can be observed in the surface layer (to 

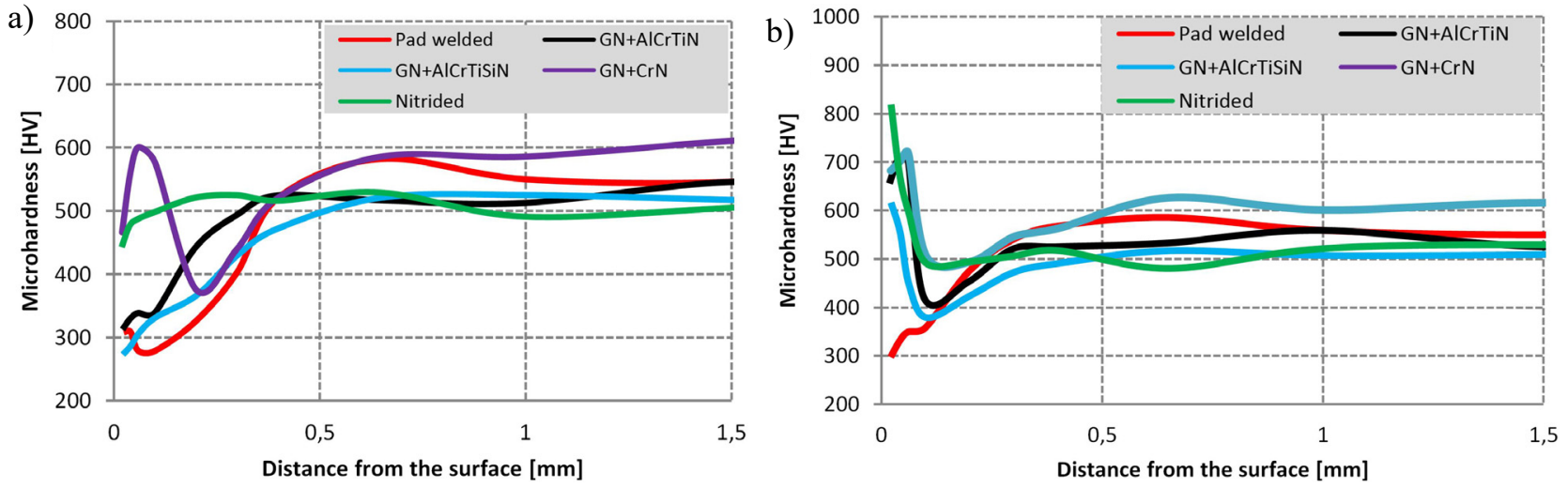

Fig. 17. Microhardess distribution on the die front (area A) in: a) point 2 and b) point 3

a)

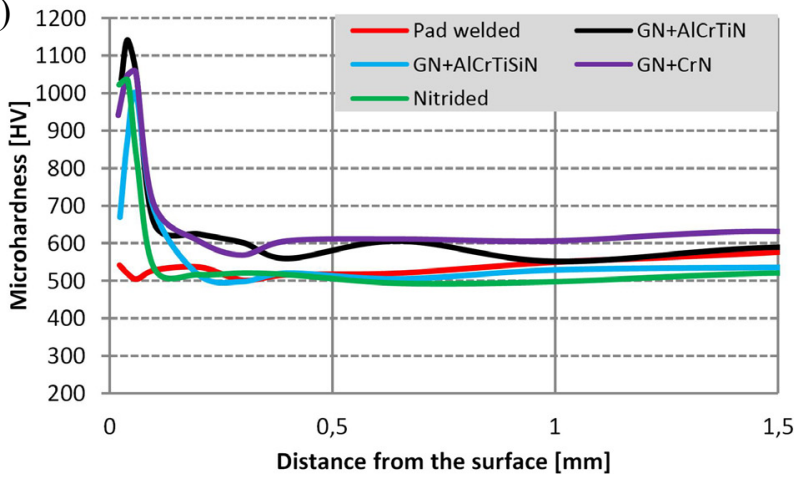

b)

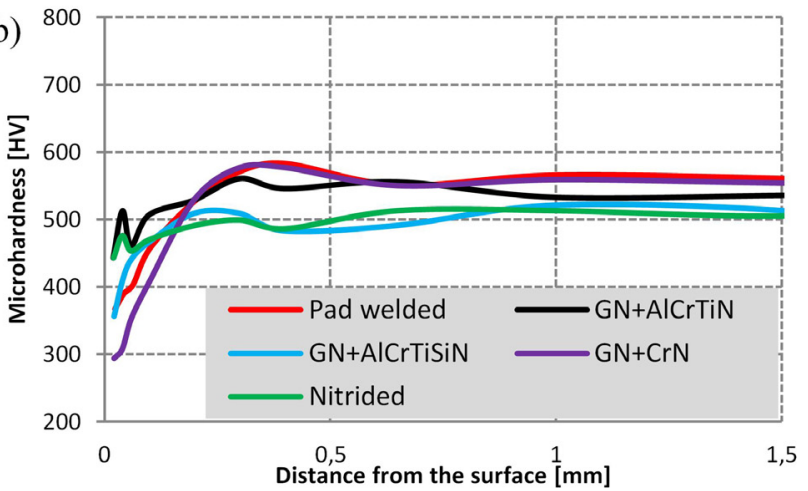

Fig. 18. Microhardness distribution on the die surface (area B) in: a) point 9 and b) point 10

about $0,5 \mathrm{~mm}$ ). This decrease is the most clearly observed for the pad welded insert, which can be explained by the tempering of the material as a result of the longest contact with the heated material. As the determined microhardness distributions have shown, the applied hybrid layers, to some extent, protect the surface from the disadvantageous operation of high temperature, especially for the $\mathrm{GN}+\mathrm{CrN}$ layer.

In point no. 3 (Fig. 17b), the drop of hardness is observed only for the pad welded insert, which can be caused by the lack of a protective layer, as opposed to the other inserts. The behaviour of the layer with an elevated hardness was confirmed by the scanning of the surface, which showed the lowest loss of material in this point for the nitrided inserts, the ones with the coatings and without one.

For area B, in point no. 9 (Fig. 18a), the protective layer was preserved for all the inserts, except for the pad welded one, whose hardness equaled the hardness of the core. In point no. 10 (Fig. 18b), in the area where the material's flow into the groove on the flash was the most intensive, one can see a drop of hardness for all the analyzed inserts. This drop is similar for all the inserts, regardless of the number of performed forgings. As it was confirmed by the microstructural tests and scanning, in this point, the protective layer underwent a complete wear. Additionally, the performed microhardness measurements for the pad welded insert, at a longer distance from the surface, showed that the pad welded layer does not undergo abrasion at all, but remains till the end of the tool performance, effectively limiting its wear.

\section{Conclusions}

The proposed reverse 3D scanning method enables a fast quantitative analysis of the shape changes in the forging tools (especially when the die insert is divided into smaller selected areas) based on the periodically collected forgings. It also makes it possible to measure the progress of the tool wear, which is important, as the wear proceeds in phases, rather than steadily. Such wear was observed for the inserts with the hybrid layers, which initially remained without the loss of volume, and next they spalled rapidly, undergoing accelerated abrasion. What is more, the further analysis with the use of scanning, also confirmed by other (microstructural and hardness) tests, proved the effectiveness of the reverse 3D method by confirming the total loss of the tool material as being in accordance with the loss measured on the basis of the periodically collected forgings. At the same time, it was noticed that, sometimes, during the forging volume measurement, errors occur, caused by incomplete filling of the shape of the forging or by its damage, which disturb the wear measurement performed by the volumetric method. They result in an artificial volume growth of the tool, impossible to be accepted as positive wear. This disturbance was successfully eliminated by way of reducing the analyzed area to small fragments of the forging.

The presented research proved that the modifying properties of the surface layer by way of applying hybrid techniques, such as hybrid layers of the nitrided layer/PVD coating type, make it 
possible to effectively improve the durability of forging tools in hot forging processes. Good effects were also obtained with the application of pad welding of the insert, despite the fact that it was not coated with any protective layer. The analysis showed that the hybrid layer with the $\mathrm{GN}+\mathrm{CrN}$ coating exhibits the best performance properties in all the analyzed areas, which can be related with its higher fatigue resistance, elasticity, adhesion, as well as higher thickness connected with thermal resistance (Table 1). Good performace properties were also observed for the GN+AlCrTiN layer, which is less sensitive to friction, detachment and spalling, but more susceptible to deep cracking. However, in area B, the results of the $\mathrm{GN}+\mathrm{CrN}$ layer were similar to those of the other hybrid layers and the pad welded insert because of their similar resistance to abrasive wear. The weakest results in area A were obtained for $\mathrm{GN}+\mathrm{AlCrTiSiN}$, which very quickly looses its coating and undergoes strong abrasive wear, intensified by the detachment of small and hard particles of nitrides, working as an abrasive material.

\section{Acknowledgments}

This study was funded by project no. NCBiR PBS2/A5/37/2013. entitled "Application of advanced PV + PVD hybrid layers dedicated to increasing tool life in forging processes".

\section{REFERENCES}

[1] Z. Gronostajski, M. Hawryluk, Archives of Civil and Mechanical Engineering 8 (2) 39-56 (2008).

[2] Z. Gronostajski, M. Kaszuba, M. Hawryluk, M. Zwierzchowski, Archives of Civil and Mechanical Engineering 14 (4), 528-539 (2014).

[3] Ch. Choi, A. Groseclose, T. Altan, Journal of Materials Processing Technology 212 (8) 1742-1752 (2012).

[4] D.H. Kim, H.C. Lee, B.M. Kim, K.H. Kim, Journal of Materials Processing Technology 212, 1742-1752 (2012).

[5] P. Anders, S. Hogmark, J. Bergström, International Journal of Fatigue 10, 1095-1107 (2004).

[6] A. Katunin, Archives of Civil and Mechanical Engineering 11 (2), 333-342 (2011).
[7] A. Person, S. Hogmark, J. Bergstrom, Surface \& Coatings Technology 191, 216-227 (2005).

[8] G.A. Berti, M. Monti, Fatigue \& Fracture of Engineering Materials \& Structures 28 (11), 1025-1034 (2005).

[9] J.F. Archard, Journal of Applied Physics 24, 981-988 (1953).

[10] M. Hawryluk, J. Ziemba P. Sadowski, Measurement and Control 50 (3), 74-86 (2017).

[11] L. Lavtar, T. Muhic, G. Kugler, M. Tercelj, Engineering Failure Analysis 18 (10), 1143-1152 (2011).

[12] Y. Min, X. Wu, Journal of Shanghai University 5 (4), 326-330 (2001).

[13] B. Lu, H. Ou, H. Long, Structural and Multidisciplinary Optimization 44, 529-545 (2011).

[14] F. Meng, K. Tagashira, R. Azuma, H. Sohma, ISIJ International 34 (2), 205-210 (1994).

[15] M. Yong-an, W. Xiao-chun, X. Luo-ping, T. Wen-jun, Journal of Shanghai University 5 (4), 326-330. (2001).

[16] C. Starling, J. Branco, Thin Solid Films 308 (309), 436-442 (1997).

[17] A. Taylan, N. Gracious, S. Gangshu, ASM Inter. Asm metals handbook 14, 337-338 (2005).

[18] A. Meller, S. Legutko, J. Smolik, Archiwum Technologii Maszyn i Automatyzacji 30 (4), 199-211 (2010).

[19] Z. Gronostajski, M. Kaszuba, M. Hawryluk, M. Marciniak, M. Zwierzchowski, A. Mazurkiewicz, J. Smolik, Metallurgy 54 (4), 687-690 (2015).

[20] K. Lange, L. Cser, M. Geiger, J.A.G. Kals, Proceedings of the Institution of Mechanical Engineers, Part B: Journal of Engineering Manufacture November 207, 223-239 (1993).

[21] K.S. Klimek, H. Ahn, I. Seebach, M. Wang, K.T. Rie, Surface and Coatings Technology, 174-175, 677-680 (2003).

[22] T. Yilkiran, B.A. Behrens, H. Paschke, M. Weber, H. Brand, Archives of Civil and Mechanical Engineering 12, 284-291 (2012).

[23] Z. Gronostajski, M. Hawryluk, M. Kaszuba, J. Ziemba, Eksploatacja i Niezawodnosc - Maintenance and Reliability 18 (2), 194-200 (2016).

[24] M. Hawryluk, Archives of Civil and Mechanical Engineering 16 (4), 845-866 (2016).

[25] M. Hawryluk, J. Jakubik, Engineering Failure Analysis 59, 396409 (2016).

[26] J. Turek, Politechnika Krakowska, Trwałość matryc kuźniczych z wykrojami napawanymi, 2010 Kraków. 